\title{
Accuracy of Ultrasonography in Detecting Radiolucent Soft Tissue Foreign Bodies
}

\author{
Sudheendraswamy V.B. ${ }^{1}$, Rudresh Halawar ${ }^{2}$ \\ ${ }^{1}$ Assistant Professor, ${ }^{2}$ Associate Professor, S. Nijalingappa Medical College, Bagalkot, Karnataka, India
}

Corresponding author: Dr. Rudresh Halawar, Department of Radio-Diagnosis and Imaging, S. N. Medical College, Navanagar, Bagalkot. Karnataka. 587101, India

DOI: http://dx.doi.org/10.21276/ijcmsr.2020.5.1.19

(c) BY-NC-ND

How to cite this article: Sudheendraswamy V.B., Rudresh Halawar. Accuracy of ultrasonography in detecting radiolucent soft tissue foreign bodies. International Journal of Contemporary Medicine Surgery and Radiology. 2020;5(1):A85-A87.

\section{A B S T R A C T}

Introduction: In emergency departments(ED's), wounds which are open are common complaints. The foreign body for long periods may remain asymptomatic. Metal, glass and wood are the most common retained foreign bodies. This study assessed the effectiveness of ultrasonography in detecting the soft tissue foreign bodies.

Material and Methods: This study was conducted from October 2017 to November 2018 in S Nijalingappa Medical College, Bagalkot, Karnataka.

Results: Sixty patients were selected to undergo removal of foreign body under ultrasonography guided removal or surgical exploration. 55 patients had foreign bodies i.e. 36,14,4 and 1 case had thorn, wood, glass, and plastic respectively. USG was positive in 58 patients. In five cases, foreign body presence was detected falsely by USG and was falsely negative in two cases. 91.8\%, 98\% and 93\% were the accuracy, sensitivity and PPV respectively.

Conclusion: It is recommended to use high resolution USG for evaluating and detecting radiolucent foreign bodies in patients as it is easily available, highly sensitive and due to its absence of radiation.

Keywords: Foreign Bodies, Emergency Departments.

\section{INTRODUCTION}

In patients visiting emergency departments, the most common are penetrating foreign bodies. ${ }^{1}$ The foreign body for long periods may remain asymptomatic or it may lead to a wide range of complications which include pain, abscess, chronic discharging wound, necrotizing fasciitis, bone and joint destructive lesions, granulomas, with tendon mobility impairment or digits triggering, migration, delayed tendon ruptures, neurodeficits, pyogenic granulomas and vascular events. ${ }^{2}$ Prolonged operational and massive soft tissue injury is lead by pre-operative localization errors. In emergency departments(ED's), open wounds are common complaints. ${ }^{3}$ They account for $4.5 \%$ of total ED visits. In initial evaluation of physician, retained foreign bodies are found to be in $7 \%$ to $15 \%$ of wounds in the ED and upto $38 \%$ are missed. ${ }^{4} 24$ hours is the ideal treatment window for retained bodies, which allows entry and exit visualization of wounds and decreased inflammation, induration and scarring. Complications such as infection delayed wound healing, inflammation, and function loss are lead by delayed treatment. Removal attempts also may result in further tissue damage, foreign body migration or retention, infection and neurological damage. Diagnosis failure of retained soft tissue foreign bodies may result in medical malpractise claims and large indemnity payments. The most common retained foreign bodies are metal, glass and wood. General evaluation of a retained foreign bodies includes a detailed history and physical examination and plain film radiographs. Glass and wood are radioluscent and difficult to observe on radiograph images. $50 \%$ of missed foreign bodies using physical examination and radiographs accounts to glass and only $7.4 \%$ sensitivity are plain radiographs in identifying wood foreign bodies. ${ }^{5}$ Ultrasonography is a diagnostic tool which is readily available, easy to use, lack of radiation and safe in detecting soft tissue foreign bodies in emergency departments. To use ultrasonography more effectively, understanding the capabilities of diagnosis of ultrasonography in identifying soft tissue foreign bodies will allow emergency physicians. This study assessed the effectiveness of ultrasonography in detecting the soft tissue foreign bodies.

\section{MATERIAL AND METHODS}

This study was conducted from October 2017 to November 2018 in S Nijalingappa Medical College, Bagalkot, Karnataka. Patients with suspicious soft tissue foreign body were referred to radiologist for a soft tissue sonographic examination and foreign body localization. All the radiographs were reviewed by radiologists. The patients who showed positive sonographic examination were referred to surgical exploration or USG guided removal. Scans of USG were performed in sagittal, coronal, and axial planes. For better spatial resolution, high frequency transducer was used. By USG, after detecting the soft tissue foreign body, characterizing the size, location, 
relationship, depth, and orientation of the foreign body to other structures such as muscle, tendon, bone and vessels. Foreign body removal was carried out by direct USG vision or surgical exploration. For each of the patients, the overall percent values of accuracy, sensitivity, specificity, positive predictive value, and negative predictive values were derived. Using McNemar's symmetry test, the difference between sensitivity and specificity for each of the patient was tested for significance. SPSS 16.0 was used to analyse the data.

\section{RESULTS}

Sixty patients were selected in the study to undergo removal of foreign body under ultrasonography guided removal or surgical exploration.

Table 1 shows that male patients were 50 (83.3\%) which was more than female patients which constituted to $10(16.7 \%)$. Mean age of patients was $25.67 \pm 12.5$ (range of $1.8-55$ years). Patient complaint duration was from 1 day to 6 years, it was less than a month for $50 \%$ of cases.

Table 2 shows predominant chief complaints which were foreign body sensation was seen in 28 patients (46.6\%),

\begin{tabular}{|l|c|c|}
\hline Demographics & Males $(n, \%)$ & Females $(n, \%)$ \\
\cline { 2 - 3 } & $50(83.3 \%)$ & $10(16.7 \%)$ \\
\hline Mean Age & \multicolumn{2}{|c|}{$25.67 \pm 12.5(1.8-55$ Years $)$} \\
\hline \multicolumn{3}{|c|}{ Table-1: Demographics } \\
\hline
\end{tabular}

\begin{tabular}{|l|c|c|}
\hline Predominant Chief complaints \\
\hline Chief complaints & $\begin{array}{c}\text { Number of } \\
\text { patients }\end{array}$ & Percentage \\
\hline Foreign body sensation & 28 & $46.6 \%$ \\
\hline Discharging wound & 18 & $30 \%$ \\
\hline Pain & 14 & $23.4 \%$ \\
\hline \multicolumn{3}{|c|}{ Table-2: Predominant chief complaints } \\
\hline
\end{tabular}

\begin{tabular}{|l|c|c|}
\hline USG results & Number of patients & Percentage \\
\hline Negative & 2 & $3 \%$ \\
\hline Positive & 58 & $97 \%$ \\
\hline Total & 60 & $100 \%$ \\
\hline Table-3: USG results of the patients who were explored for \\
foreign body \\
\hline
\end{tabular}

\begin{tabular}{|l|c|c|}
\hline Surgical results & Number of patients & Percentage \\
\hline Negative & 5 & $9 \%$ \\
\hline Positive & 55 & $91 \%$ \\
\hline Total & 60 & $100 \%$ \\
\hline \multicolumn{2}{|c|}{ Table-4: Surgical results } \\
\hline
\end{tabular}

\begin{tabular}{|l|c|c|}
\hline Nature & Number of patients & Percentage \\
\hline Thorn & 36 & $60 \%$ \\
\hline Plastic & 1 & $2 \%$ \\
\hline Wood & 14 & $23 \%$ \\
\hline Glass & 4 & $7 \%$ \\
\hline Calcified granuloma & 1 & $2 \%$ \\
\hline \multicolumn{2}{|c|}{ Table-5: Nature of foreign body } \\
\hline
\end{tabular}

discharging wound was seen in 18 patients (30\%), pain was seen in 14 patients (23.4\%). 11 cases did not use the USG examination as they had a history of surgical exploration, in which no foreign body was detected. $100 \%$ of the foreign bodies were echogenic.

USG results showed that 2 patients were negative and 58 patients were positive for foreign bodies (table-3).

Surgical results showed that 5 patients were negative and 55 patients were positive for foreign bodies (table-4).

Foreign body was successfully removed in 53 patients who underwent surgical exploration or USG guided removal. 2 patients with a negative USG examination were symptomatic and there was no response to medical therapy were explored surgically and a $6 \mathrm{~mm}$ thorn was detected and removed. Due to presence of air bubbles and scar tissue, in 4 cases, USG was falsely positive in failed surgical exploration and in one case, calcified granuloma was detected.

Thorn, plastic, wood, glass were the foreign bodies. Foot, hand, leg, arm, forearm, ankle, knee, wrist, thigh were the foreign bodies sites. 5 to $52 \mathrm{~mm}$ was the size of the foreign body. In $50 \%$ of the cases, the size of the foreign body was more than $14 \mathrm{~mm} .91 .8 \%, 98 \%$ and $93 \%$ were the accuracy, sensitivity and PPV of this study (table-5).

\section{DISCUSSION}

To rule out the radiopaque foreign objects presence, conventional radiographs should be used. These are easy to detect, but radiolucent foreign bodies like wood are difficult to detect and usually missed. For decades, the foreign bodies which are missed may tend to produce immediate symptoms like wound infections or may remain asymptomatic. In Anderson et $\mathrm{al}^{6}{ }^{6}$ all the standard radiographs were negative which was comparable to this study. In their study, $15 \%$ and $7 \%$ of radiolucent foreign bodies appeared in radiographic studies respectively. This study proves that USG is a highly sensitive and accurate modality in detecting radiolucent foreign bodies that are difficult to be seen in standard radiographs. Overall sensitivity and PPV was 52.6\% and $79.9 \%$ respectively in Chad et al study. ${ }^{7}$ In Chad et al study, the live human tissue was not optimally represented and USG was performed by emergency physicians under training whereas in our study, it was done by expert radiologist. An invitro study was conducted by Ibrahim Turkcuer et $\mathrm{al}^{8}$, in which overall sensitivity and PPV of USG in detecting foreign bodies was $90 \%$ and $81 \%$ respectively. But when compared to our study, their's was an in vitro study, in which chicken thighs were used. In Michael Orlinsky et $\mathrm{al}^{9}$ study, the overall accuracy, sensitivity, and PPV of USG determined by radiologist in detecting radiolucent foreign body were $83 \%, 83 \%$ and $83 \%$ respectively, but in this study also chicken thighs were used. In Gilbert and Campbell's study ${ }^{10}$, the detection of foreign bodies was done in 24 patients, (21 true positive and 3 false positive). The sensitivity was $95.4 \%$ in their study and wood was the most common foreign body whereas in our study, the overall sensitivity was $98 \%$ and thorn was the most common foreign body. Our Study was comparable with Tahmasebi Morteza et al study ${ }^{11}$, in which it was reported that 51 patients underwent USG guided or surgical exploration in removing the foreign bodies whereas 
in this study, Sixty patients were selected to undergo removal of foreign body under ultrasonography guided removal or surgical exploration and in Tahmasebi Morteza et $\mathrm{al}^{11}$ study, 47 patients had foreign bodies i.e. 31,12,3 and 1 case had thorn, wood, glass, and plastic respectively whereas in the present study, 55 patients had foreign bodies i.e. 36,14,4 and 1 case had thorn, wood, glass, and plastic respectively. In Tahmasebi Morteza et $\mathrm{al}^{11}$ study, Ultrasound was positive in 50 patients whereas in the present study, USG was positive in 58 patients. In Tahmasebi Morteza et $\mathrm{ll}^{11}$ study, in four cases, foreign body presence was detected falsely by USG and was falsely negative in one case whereas in the present study, in five cases, foreign body presence was detected falsely by USG and was falsely negative in two cases. In Tahmasebi Morteza et $\mathrm{al}^{11}$ study, accuracy, sensitivity and positive predictive values were $90.2 \%, 97.9 \%$ and $92 \%$ respectively, whereas in the present study, 91.8\%, 98\% and 93\% were the accuracy, sensitivity and PPV respectively. Important information about size, depth, and relationship of foreign bodies with other structures such as vessels and tendons is provided by USG and it makes easier exploration for the surgeon. Another advantage of USG is under sterile conditions, it makes the real time guided removal of foreign bodies possible and it is safe and less complicated, it may replace surgical exploration.

\section{CONCLUSION}

This study showed that a higher accuracy and sensitivity for USG in detecting the radiolucent foreign bodies was observed compared to other studies. It is recommended to use high resolution USG for evaluating and detecting radiolucent foreign bodies in patients as it is easily available, highly sensitive and due to its absence of radiation.

\section{REFERENCES}

1. Boyse TD, Fessell DP, Jacobson JA, Lin J, Van Holsbeeck MT, Hayes CW. USG of soft tissue foreign bodies and associated complications with surgical correlation. Radiographics 2001;21(2):1251-6.

2. Saki N, Nikakhlagh S, Rahim F, Abshirini H. Foreign body aspirations in infancy: A 20 year experience. Int J Med Sci 2009;6(5):322-8

3. Yanay O, Vaughan DJ, Diab M, Brownstein D, Brogan TV. Retained wooden foreign body in a child's thigh complicated by severe necrotizing fasciitis: A case report and discussion of imaging modalities for early diagnosis. Pediatric Emergency Care, 2001;17(6):354-5.

4. Fakoor M. Prolonged retention of an intra-medullary wooden foreign body. Pak J Med Sci, 2006;22(3):78-9.

5. Flom LL, Ellis GL. Radiologic evaluation of foreign bodies. Emerg Med Clin North Am, 1992; 10(1):16377.

6. Anderson MA, William L Newmeyer III, Eugene S Kilgore; Diagnosis and treatment of retained foreign bodies in the hand; The American Journal of Surgery 1982;144(2):63-67.

7. Chad S Crystal, David A Masneri, John S Hellums, David W Kaylor, Scott E Young, Michael A Miller, Marc E Levsky; Beside ultrasound for the detection of soft tissue foreign bodies: A cadaveric study; The journal of Emergency Medicine 2009;36(4):377-380.
8. Turkcuer I, Atilla R, Topacoglu H, Yanturali S, Kiyan S, Kabakci N, et al. Do we really need plain and soft- tissue radiographies to detect radiolucent foreign bodies in the ED. Am J Emerg Med. 2006;24(5):763-8.

9. Orlinsky M, Knittel P, Feit T, Chan L, Mandavia D. The comparative accuracy of radiolucent foreign body detection using ultra sonography. Am J Emerg Med. 2000;18(1):401-3.

10. Gilbert FJ, Campbell RSD, Bayliss AP. The role of ultrasound in the detection of non-radiopaque foreign bodies. Clin Radiol. 1990;41(4):109-12.

11. Morteza Tahmasebi, Hamdollah Zareizadeh, and Azim Motamedfar; Accuracy of ultrasonography in detecting radiolucent soft-tissue foreign bodies; Indian Journal of Radiology imaging, 2014; 24(2):196-200.

Source of Support: Nil; Conflict of Interest: None

Submitted: 26-12-2019; Accepted: 21-01-2020; Published online: 17-02-2020 